\title{
Strategies and Tactics for the Synthesis of Complex Alkaloids
}

\author{
Scott A. Snyder*
}

\begin{abstract}
Efforts to achieve the laboratory synthesis of complex natural products have long served as a means to advance the science of organic chemistry. Indeed, core physical organic principles, new reagents and synthetic transformations, effective strategies for stereocontrolled synthesis, and useful pharmaceutical agents are but a few advances that have issued from such endeavors over the course of the past century. Within this review are recounted selected research programs from the author's laboratory seeking to add to that repertoire of discoveries by targeting complex polycyclic alkaloids for synthesis. Advances resulting from these studies include new strategies for the rapid synthesis of intricate molecular domains, reaction processes and sequences capable of accessing a range of diversity across several alkaloid classes, examples of achieving family-level synthetic solutions from common synthetic building blocks, and a unique perspective on effecting the laboratory synthesis of dimeric materials when direct mergers fail.
\end{abstract}

Keywords: Polycyclic alkaloids

Throughout organic chemistry's history, naturally-derived alkaloids have played an essential role in the progression of the field. For example, throughout the late part of the $19^{\text {th }}$ century as well as for most of the first half of the $20^{\text {th }}$ century, efforts to elucidate as well as synthesize the structures of complex alkaloids such as quinine and strychnine (1 and $\mathbf{2}$, Fig. 1) served as the means to establish much of the foundation for modern heterocyclic chemistry. ${ }^{[1,2]}$ Similarly, efforts to understand and harness their biological properties have afforded countless therapies that have extended the length and quality of life; vinblastine (3) is but one example that has been essential to the development of powerful treatments for varied forms of cancer. ${ }^{[3]}$
Despite this rich history, numerous opportunities for further discoveries remain, especially as additional, structurally unique alkaloids are isolated from varied natural sources throughout the globe. Indeed, it is several such alkaloids that have inspired our group to devote significant research attention over the past several years to try and develop strategies, tactics, and methods to prepare them through step-economic routes with transformations of potentially broad applicability to diverse target molecules. In this review, several examples of these efforts are recounted in hopes of revealing some of our global programmatic logic as well as some areas worthy of future investigation.

One of our first major forays in alkaloid natural product chemistry sought to tackle the complexity posed by the Securinega family, select members of which (4-6) are shown in Scheme 1. ${ }^{[4]}$ Although these and other related compounds have been the subject of a number of successful and creative synthetic endeavors over the years, ${ }^{[5]}$ we were struck, in particular, by the general difficulty encountered in forging the bridging butenolide domains (highlighted here in blue) which are a shared and sig- nature structural element of the collection. Indeed, for most published approaches, a significant proportion of the total number of synthetic operations were dedicated to its construction. We wondered whether an appropriate precursor along with a cascade-based set of bond constructions could more readily fashion such butenolides in a manner that could be applicable to the class as a whole.

Our idea, shown as a general approach in the middle part of Scheme 1, sought to determine whether an $\mathrm{N}$-heterocyclic carbene $(\mathrm{NHC})^{[6]}$ derived from an appropriate pre-catalyst $(\mathbf{8})$ could enable a pendant enynal such as $\mathbf{7}$ to attack the neighboring ketone in an Umpolung fashion to generate 10. ${ }^{[7]}$ This event would set the stage for a lactonization to complete the entire bridging framework in the form of $\mathbf{1 2}$ and regenerate the NHC promoter in a single step. While appealing on paper, we were unsure at the outset of our studies as to just how readily such a precursor could be forged. We were also uncertain as to whether such an ynal could even behave as a homoenolate, particularly in the presence of an enolizable ketone that might readily engage in intramolecular Michael chemistry with the

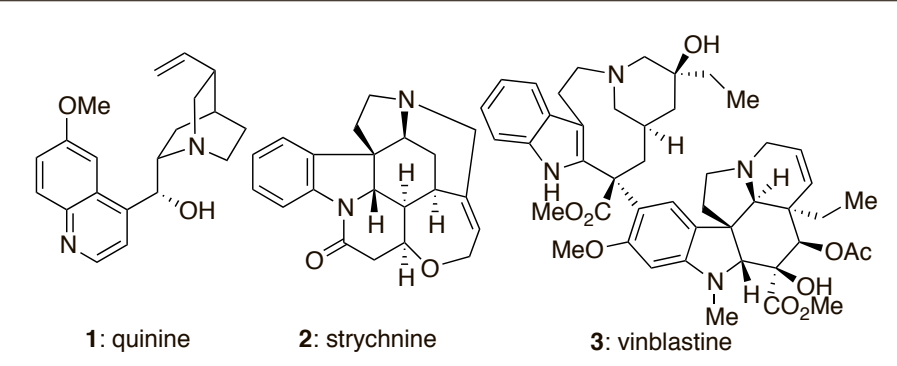

Fig. 1. Structures of selected alkaloids that have deeply impacted chemical synthesis and pharmaceutical science. 
ynal rather than participating in the proposed NHC-promoted reaction.

As matters transpired, such enynals could be prepared, albeit under carefully orchestrated conditions, and we found that the desired cyclization cascade could be conducted effectively only under a very narrow range of conditions using a large amount of NHC pre-catalyst $\mathbf{1 4}$ $(40 \mathrm{~mol} \%)^{[8]}$ in the presence of a stoichiometric amount (2.0 equiv.) of a Lewis acid promoter in the form of $\mathrm{Ti}(\mathrm{O} i-\mathrm{Pr})_{4}{ }^{[9]}$ Other NHC mediators, at least in model studies, failed to provide any improved throughput, and other Lewis acid additives proved entirely ineffective; slow addition of the substrate into the NHC/Lewis acid mixture was also critical for success. As shown for the substrates probed $(\mathbf{1 3}, \mathbf{1 6}$, and 18), yields were variable depending on their overall complexity (31\% to $91 \%$ ). Nevertheless, three different frameworks pertinent to the class could be accessed in a single pot through the developed cascade. Of these, compound $\mathbf{2 0}$ is perhaps the most significant from the standpoint of comparison to past approaches, in that it was obtained in nine steps overall; a longer sequence was recently described for a synthesis of its hydroxylated counterpart, secu' amamine A (6). ${ }^{[5 r]}$

In a similar spirit of seeking to achieve the rapid construction of a complex framework, as well as explore additional opportunities to develop new chemistry, we were also attracted to the molecular framework of scholarisine A (29, Scheme 2). ${ }^{[10]}$ This unique member of the Akuammiline family of alkaloids ${ }^{[11]}$ possesses an indolenine fused onto a strained carbocyclic cage in a final structure that contains a total of six chiral centers, two of which are quaternary. Our plan ${ }^{[12]}$ was to identify an efficient approach to prepare that novel carbocyclic core, and then find a means to fuse the indolenine ring onto it, potentially through a unique, late-stage operation as opposed to more conventional heterocycle-forming reactions such as the Fischer indole synthesis which has long been a mainstay in the preparation of diverse indole alkaloids.

The key processes we developed to achieve these goals are delineated in Scheme 2, starting with a Diels-Alder reaction between dienophile $\mathbf{2 1}$ and pyrone 22 to deliver bicyclic lactone 23. As long as there was a cyclic protecting group engaging the amine and alcohol of the serinederived precursor (as in $\mathbf{2 1}$ ), the cycloaddition proceeded with a reasonable degree of diastereoselectivity, here in an $\sim 3: 1$ ratio to afford the desired product along with its separable diastereomer in $83 \%$ combined yield. It is noteworthy, though, that this process proceeded so effectively, in that the ester appended to the pyrone diene system would appear to render this material an in-

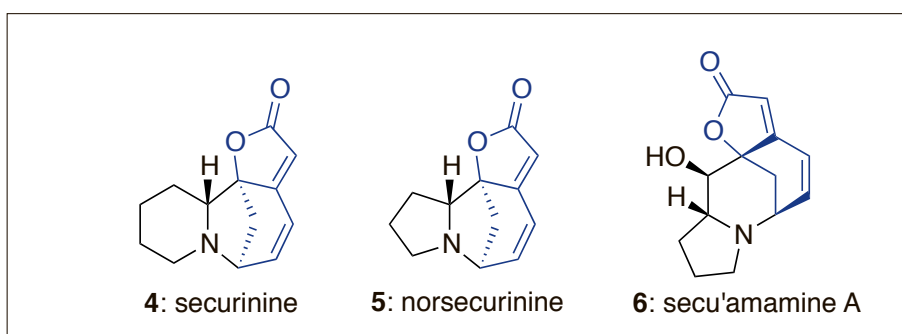

Scheme 1. Development of an approach for the rapid assembly of the bridging butenolide domains of the Securinega alkaloids.

General approach:
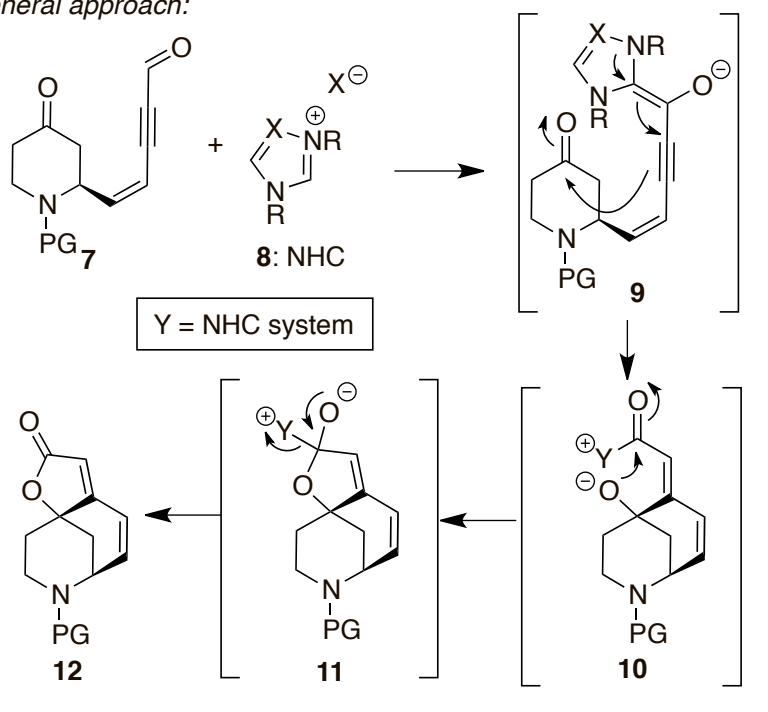

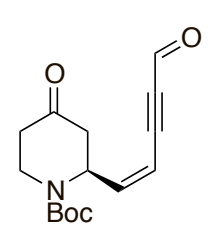

(士)-13

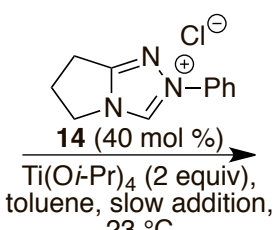

$23^{\circ} \mathrm{C}$

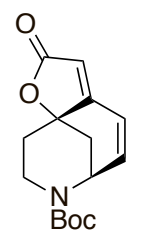

$( \pm)-15$

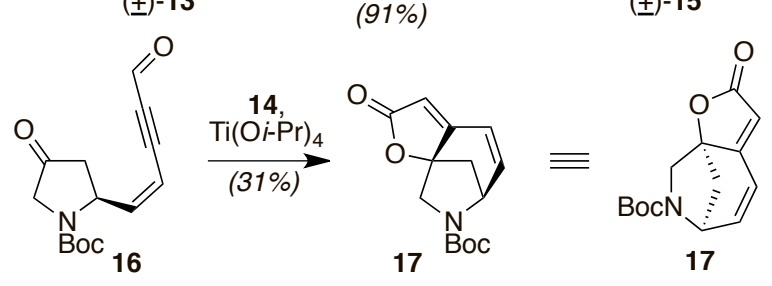

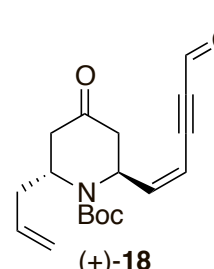

(土)-18

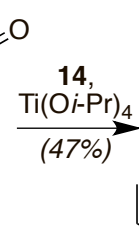

$\mathrm{O}$

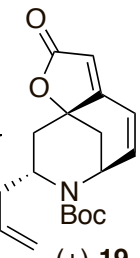

(土)-19

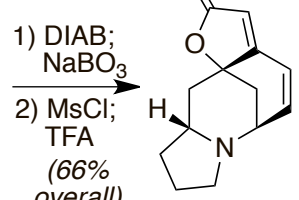

(士)-20 verse-demand partner, here combined with a conventional electron-deficient dienophile; nevertheless, this reaction proceeded smoothly at $100{ }^{\circ} \mathrm{C}$ without degradation of the lactone product through a potential retro-[4+2] process expelling $\mathrm{CO}_{2}$. Indeed, the facility of this reaction with the ester group in place was of critical strategic importance, in that this group aided a subsequent radical-based cyclization cascade of 24 (prepared from 23 in two steps) initiated by $\mathrm{Et}_{3} \mathrm{~B}$ and terminated by trapping with allyltri- $n$-butylstannane to generate polycycle 25. ${ }^{[13]}$ From here, a lactamization se- quence and subsequent condensation with 2-iodoaniline afforded key substrate 26, in preparation for what we hoped would be an opportunity to develop a unique $\mathrm{C}-\mathrm{H}$ arylation reaction to generate the fused indolenine system of 27. [14] Key to note is that we had formed $\mathbf{2 6}$ as a batch dependent mixture of imine isomers (generally on the order of 2.4-2.8:1), not knowing which was the major product; that factor was important since within the substrate, two different tertiary $\mathrm{C}-\mathrm{H}$ bonds could potentially participate in the reaction process, with only one leading to the desired iso- 
mer. In the event, use of a structural derivative of $\mathrm{AIBN}$ (i.e. $\mathrm{ACHN}$ ) and $n-\mathrm{Bu}_{3} \mathrm{SnH}$ afforded 27 with 3:1 selectivity over its alternate tertiary $\mathrm{C}-\mathrm{H}$ functionalized isomer, delivering the desired compound in $18 \%$ overall yield for this critical step as well as the two preceding operations.

The completion of the synthesis then required the excision of an extra carbon atom from the previously installed allyl group and reduction of the lactam within 27 in the presence of a more accessible and reactive lactone. Following much effort, we identified the sequence shown, in which we believe the primary alcohol formed following exposure of 27 to $\mathrm{O}_{3}$ and $\mathrm{NaBH}_{4}$ was able to direct Lawesson's reagent to form the thioimidate ring of $\mathbf{2 8}$; in the absence of that alcohol, the lactam was untouched by this reagent even under forcing conditions. Two final steps (reductive removal of the bridging sulfur atom and indoline re-oxidation) completed what was a 15-step preparation of the target molecule from commercial materials. Overall, this route compares favorably to the only other completed sequence published to date.[15] Of greater importance is that these efforts have also inspired a number of additional alkaloid-based explorations by our group, both target- and method-driven.

The first of these sought to evaluate the potential for pyrone Diels-Alder chemistry ${ }^{[16]}$ to deliver indoline and hydroindoline systems pertinent to a range of molecules, ${ }^{[17]}$ including pharmaceutical agents such as CEPC (30, Scheme 3) as well as natural products like mesembrine $(31)^{[18]}$ and the more recently isolated gracilamine (32). ${ }^{[19]}$ Although these representative structures are quite different within just this key heterocyclic domain, possessing distinct oxidation states for their shared atoms colored in blue, we wondered whether it would be possible to develop a short, modular sequence that could deliver these, as well as other, related materials in a modicum of steps. Our approach $^{[20]}$ began from 4,6-dichloropyrone (33), ${ }^{[21]}$ a molecule that can be readily prepared in three steps on multigram scale but whose chemistry has not been extensively explored. What we found was that the two chlorine atoms within this starting material could be differentiated, allowing for the chemoselective replacement of one with amine-containing nucleophiles to afford substrates poised for intramolecular Diels-Alder reactions when appropriate dienophiles were built into the amine partner. For example, following acetylation of the nitrogen atom to deliver $\mathbf{3 4}$ bearing a pendant alkyne, subsequent Diels-Alder and retro-[4+2] reactions occurred upon heating at $140{ }^{\circ} \mathrm{C}$ with microwave irradiation in toluene to afford a variety of indoline frameworks with a substitution

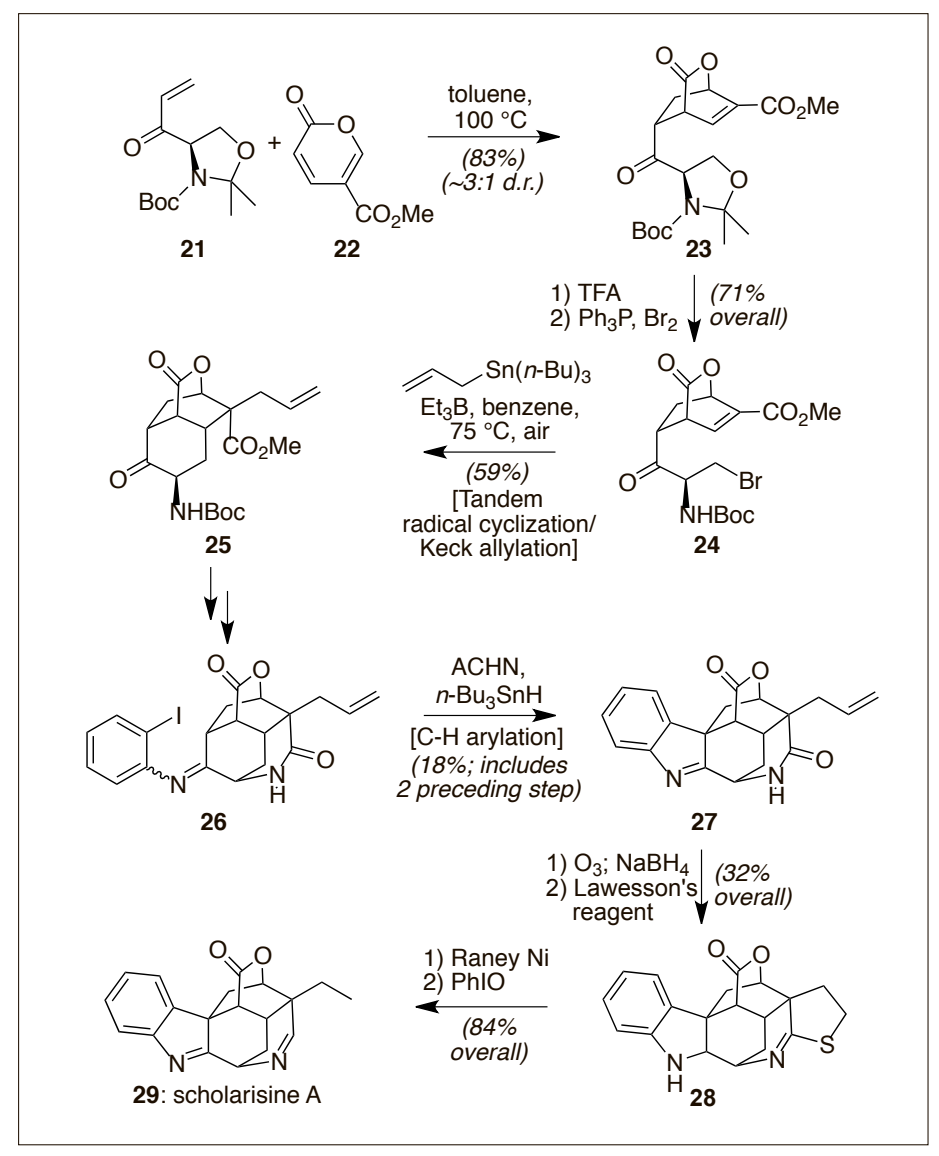

Scheme 2.

Development of an efficient route for the total synthesis of scholarisine A (29) featuring Diels-Alder chemistry as well as radical-based cyclizations to fashion its key ring systems.

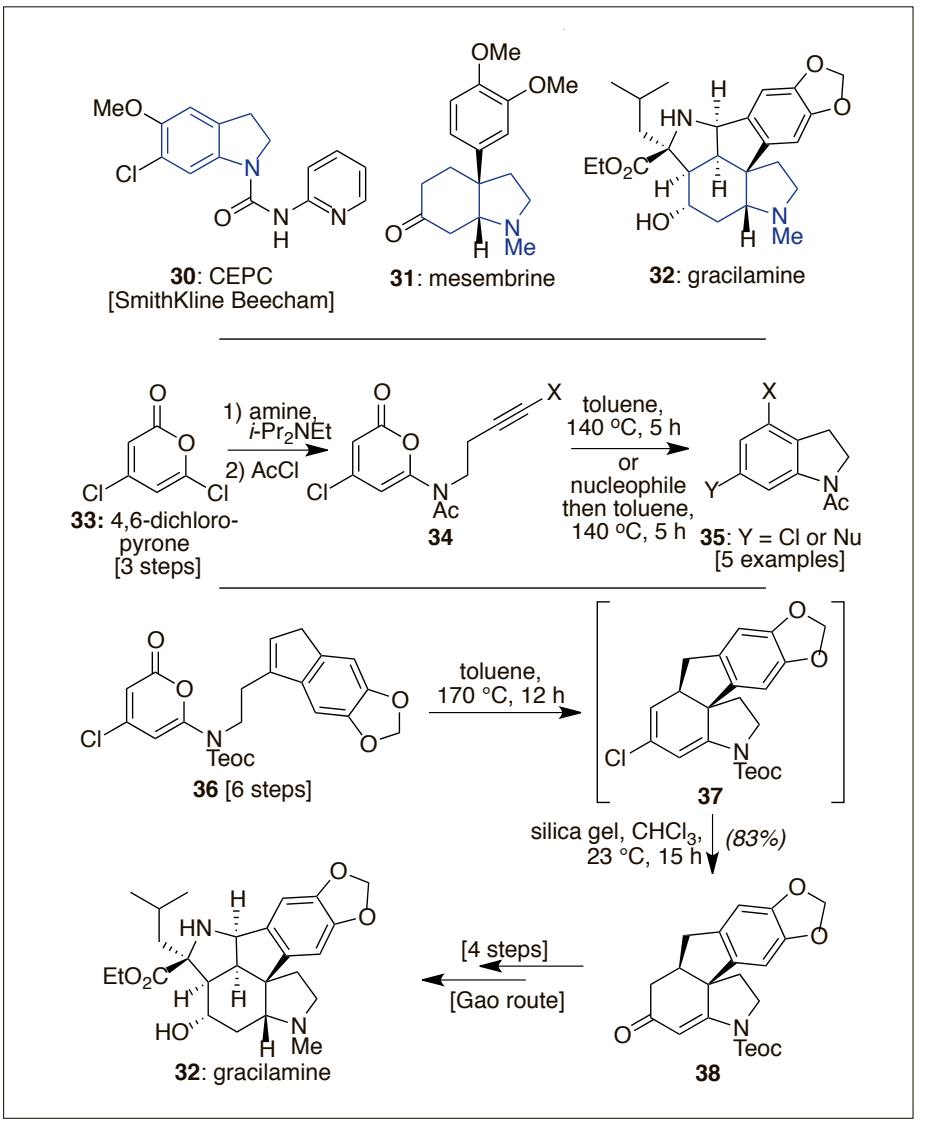

Scheme 3. Further explorations into pyrone Diels-Alder chemistry afford the means for rapid indoline and hydroindoline synthesis, with targets such as gracilamine (32) proving accessible.

pattern difficult to access through other approaches; ${ }^{[22]}$ indeed, many of the formed materials constitute previously unknown chemical entities in either their synthesized or free amine forms. On the other hand, when amines containing pendant alkenes were used instead, the opportunity to generate hydroindoline products resulted. As illustrated using compound 36, the alkene substitution pattern ensured that fol- 
lowing the key Diels-Alder/retro-[4+2] sequence a non-aromatic product would result, here in the form of dienamine 37. Pleasingly, its vinyl chloride could be hydrolyzed simply upon stirring with silica gel for several hours to afford the vinylogous amide of $\mathbf{3 8}$. Such chemistry not only afforded a concise solution in a formal total synthesis sense to gracilamine (32), ${ }^{[19 b]}$ a unique Amaryllidaceae alkaloid which was isolated in 2005[23] and has been the subject of several recent syntheses, ${ }^{[19]}$ but also simpler targets such as mesembrine (31); ${ }^{[18]}$ neither of these architectures, in our opinion, are readily traced to DielsAlder reactions as a potential key bondforming process. Essential to all of the chemistry, though, is the presence of an electron-withdrawing group on the nitrogen atom; in its absence, the Diels-Alder sequence does not proceed in any format explored to date.

As a second offshoot of our scholarisine A work, we were inspired to target other Akuammiline alkaloids with distinct structures, such as strictamine $\mathbf{( 4 5}$, Scheme 4). ${ }^{[24]}$ Although this natural product had long been devoid of any successful synthetic solutions, several teams have recently developed the means to access it in both racemic and asymmetric formats through both total and formal total syntheses. ${ }^{[25]}$ Prior to the publication of our work, the shortest asymmetric synthesis had been achieved by the Garg group (at 24 steps) ${ }^{[25 a]}$ while the most concise racemic solution was developed by the Zhu group (at 14 steps). ${ }^{[15 b]}$ Our approach, highlighted in Scheme 4, sought to develop two key reactions to achieve an even more expeditious solution. ${ }^{[26]}$ Those operations were an asymmetric propargylation of 3,4 -dihydro- $\beta$-carboline (39) and a metalmediated 6-endo-dig cyclization to generate the majority of the core. As denoted, both of those operations could ultimately be achieved. The first required significant screening of both ligands and optimization of reaction parameters to realize that $(R)$ DTBM-SEGPHOS (40) was the ideal ligand for $\mathrm{Cu}(\mathrm{I}),{ }^{[27]}$ allowing the asymmetric addition of an allenyl boronate as a convenient source of the needed carbon atoms to the imine of 39. Key to the second reaction was identifying conditions with a mixture of catalytic $\mathrm{Ph}_{3} \mathrm{PAuCl}$ and stoichiometric $\mathrm{AgSbF}_{6}$ that enabled the cyclization to proceed with an electron-deficient alkyne on a
Scheme 4.

Development of an asymmetric propargylation of 3,4-dihydro- $\beta$ carboline (39) and a metal-mediated 6 -endo-dig cyclization to rapidly forge the core skeleton of (+)-strictamine (45).

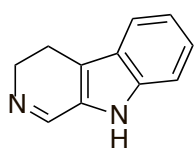

39: 3,4-dihydro$\beta$-carboline [1 step]<smiles>CC(=O)C#CC[C@H]1NCCc2c1[nH]c1ccccc21</smiles>
43 (65\%) $\mathrm{Ph}_{3} \mathrm{PAuCl}(5 \mathrm{~mol} \%)$ $\mathrm{AgSbF}_{6}(1$ equiv), $\mathrm{MsOH}$<smiles>COC(=O)C1=CCCCC12C(C(C)(C)C)=Nc1ccccc12</smiles>
44

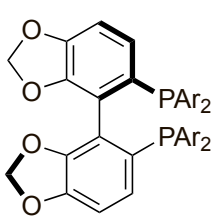

40: $(R)$-DTBM-SEGPHOS $\left(\mathrm{Ar}=3,5-\mathrm{t}-\mathrm{Bu}-4-\mathrm{MeOC}_{6} \mathrm{H}_{2}\right)$

\section{$\underset{\text { [Zhu route] }}{\stackrel{\text { [2 steps] }}{\longrightarrow}}$}

1) $40(5 \mathrm{~mol} \%)$, $\mathrm{CuCl}(6 \mathrm{~mol} \%)$, $t$-BuONa

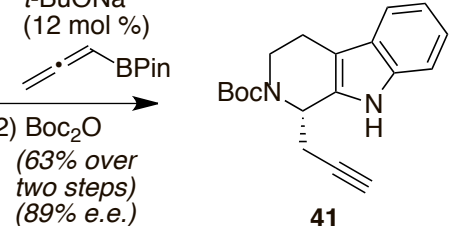

41

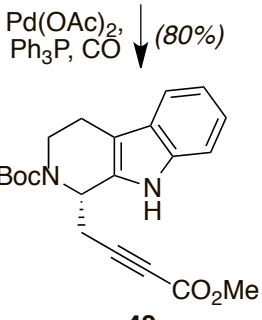

42

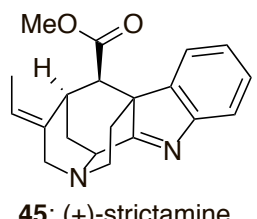

45: (+)-strictamine

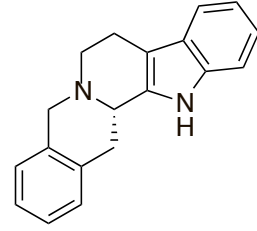

46: (S)-(-)-decarbomethoxydihydrogambirtannine substrate at the native oxidation state of the target (with the secondary amine masked as a protonated ammonium cation);[28] indeed, another team led by Fujii and Ohno used a similar 6-endo-dig process as part of their reported solution to strictamine, ${ }^{[25 c]}$ though varied protecting group and oxidation state changes required several additional steps to channel their version of the process towards 45. Overall, we were able to access intermediate $\mathbf{4 4}$ on scale in just five steps, allowing for a formal seven-step asymmetric synthesis to be achieved based on this same material being a late-stage intermediate in the Zhu route. [25b] Importantly, we believe that the developed asymmetric imine propargylation process should have applicability to a number of additional problems of significance. For example, we have already used it to achieve the first catalytic asymmetric preparation of $(S)$-(-)-decarbomethoxydihydrogambirtannine (46). [29]

Our final major program in alkaloid synthesis, one that has been pursued for several years now, is focused on a unique set of defensive compounds produced by a variety of ladybug species throughout the world. Known as the Coccinellid alkaloids, [30] these materials exist in two main forms. ${ }^{[31]}$ The first are 'monomeric' tricyclic materials, of which precoccinelline $(47$, Scheme 5), hippocasine (48), propyleine $(\mathbf{5 0})$, and isopropyleine (57) are representative examples. ${ }^{[32]}$ These materials differ in terms of some of their stereochemical elements and alkene placements which, although seemingly minor alterations in the context of two-dimensional drawings, confer substantial three-dimensional differences. The second are 'dimeric' materials, of which chilocorine B (49), psylloborine A (55), and isopsylloborine A (56) are representative; here the terminology of dimeric as used by many of the isolation teams could be potentially confusing from the perspective that the two halves of chilocorine $B$ (49) are comprised of two rather different parts. Similarly, no clear biosynthetic hypothesis for dimerization of monomeric materials has been advanced in the cases of 55 and 56, even though they might more reasonably appear to arise from structurally similar starting materials.

Our interest in the collection has been focused principally on the 'dimeric' materials, given their overall uniqueness and global synthetic challenge especially in light of their numerous quaternary and aza-quaternary chiral centers, ${ }^{[33]}$ as well as potential oxidative instability. Scheme 5 outlines one of our initial synthetic approaches in which we attempted to identify and experimentally explore a potential biomimetic synthesis for both $\mathbf{5 5}$ and $\mathbf{5 6}$ to determine if they might truly be derived from a common monomeric unit. ${ }^{[34]}$ This route was predicated on the idea that an oxida- 
tive product of molecules like propyleine (50), potentially iminium species $\mathbf{5 1}$, could serve as an active electrophile to enable a merger with another natural product starting material. As indicated by our proposal, that process would be an initial vinylogous Mannich reaction between the enamine of $\mathbf{5 0}$ and reactive intermediate $\mathbf{5 1}$ to afford 52. This event would then set the stage for a second $\mathrm{C}-\mathrm{C}$ bond forming event, again through Mannich chemistry but this time intramolecularly, that could occur follow ing a proton transfer to establish a new set of nucleophile/electrophile partners. A final loss of proton from $\mathbf{5 4}$ to restore charge neutrality would then afford psylloborine A (55) and/or isopsylloborine A (56). A key assumption of this overall proposal, outside of the feasibility of the bond formations themselves, is that pre-existing chirality within both $\mathbf{5 0}$ and $\mathbf{5 1}$ would dictate the formation of the additional stereocenters in the cascade sequence since no other chiral element would be present.

In practice, however, we were never able to realize this plan in terms of a completed synthesis of $\mathbf{5 5}$ and/or 56. Instead, what we observed was that following the in situ formation of $\mathbf{5 1}$, we could only effect its merger in a laboratory flask with the enamine isomer of propyleine, a molecule known as isopropyleine (57) that exists in solution as its equilibrium partner. This reaction process generated what we have assigned as the non-natural dimer $\mathbf{5 8}$ in $21 \%$ yield. While we do not fully understand the basis for this observed process in terms of not producing any $\mathbf{5 5}$ and/or 56, the failure to effect the desired dimerization nevertheless forced us to consider alternatives in order to achieve our goal of forming the desired products. The ultimate result was the approach shown in Scheme 6 in which, instead of bringing together two advanced, fully cyclized monomeric compounds to generate a dimer in the final step, we linked two linear precursors for each half together into a single molecule through the bond colored in red in 59. This particular bond was the one whose formation could not be effected with the proper regiocontrol through the intermolecular processes defined in Scheme 5. From here, we then executed two cascade-based operations using enamine formations, Michael additions, and Mannich chemistry to generate the additional rings of the target by forming a series of five bonds in total; we term this approach as an 'intramolecular dimerization' based on the idea that since appropriate regiocontrol could not be achieved in an intermolecular sense based on unfavorable kinetic and/or thermodynamic factors, tackling the problem in an intramolecular way might be the key to a solution, just as it has been historically in other non-dimerization contexts. ${ }^{[35]}$

Scheme 5. A biomimetic approach towards the coccinellid dimers psylloborine A (55) and isopsylloborine A (56) affords only a non-natural dimer in the form of 58 .

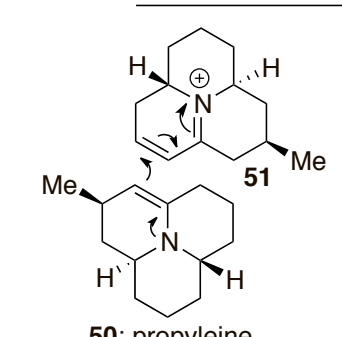

50: propyleine

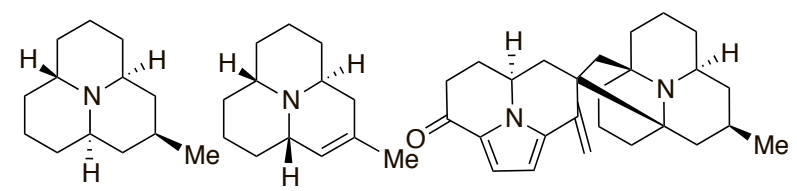

47: precoccinelline 48: hippocasine

49: chilocorine B
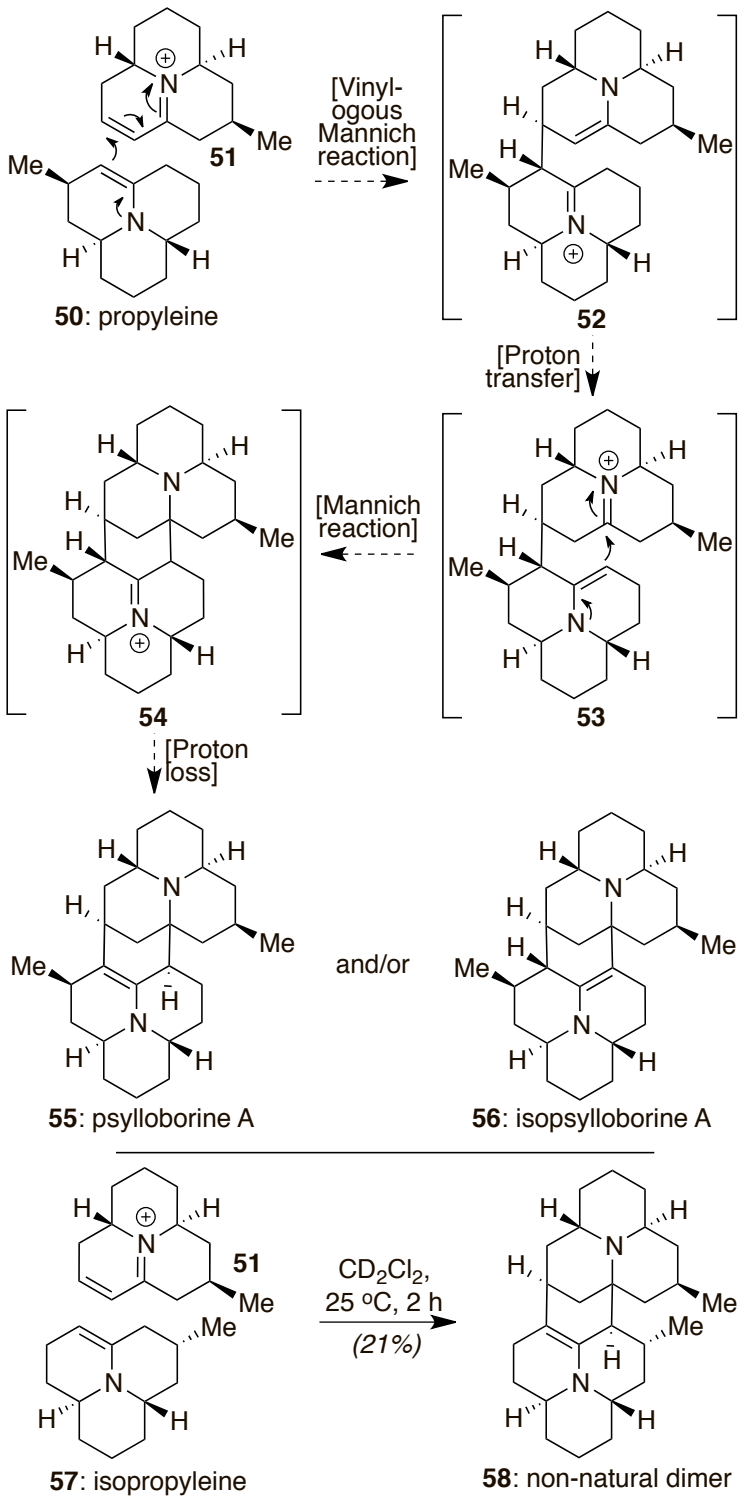

Essential to the success of this alternate approach in terms of the cascade chemistry was the use of an appended 3,5-bistrifluoromethylphenylsulfone as the electron-withdrawing group on the left-hand portion of the molecules as drawn within the intermediates. It enabled the final sequence converting 62 into 64 to proceed via the shown Michael closure followed by Mannich attack; a simple phenylsulfone afforded material (not drawn) with an initial Mannich closure from 62 without the ability to then effect the Michael reaction. In addition to providing appropriate electronic tuning of the process, this group was also the easiest of those probed to remove, allowing for completion of psylloborine A (55) in $46 \%$ yield upon exposure of 64 to
$\mathrm{Na} / \mathrm{Hg}$ amalgam. We also discovered that this natural product could be converted into isopsylloborine A (56) following its treatment with stoichiometric TFA in 1,2-dichloroethane at $70^{\circ} \mathrm{C}$. And, although not shown within the confines of these two schemes, it is worth noting that we used one key intermediate both to prepare a precursor to 59 as well as eight other monomeric natural products through formal and total syntheses, thereby affording a potentially global solution to this family; identifying such building blocks has long been a part of our global synthetic planning, including non-alkaloid-based targets. ${ }^{[36]}$

In more recent endeavors, we have sought to extend some of the key ideas from the developed chemistry in this pro- 


$$
\text { (1): } \mathrm{B}=\mathrm{Boc}
$$
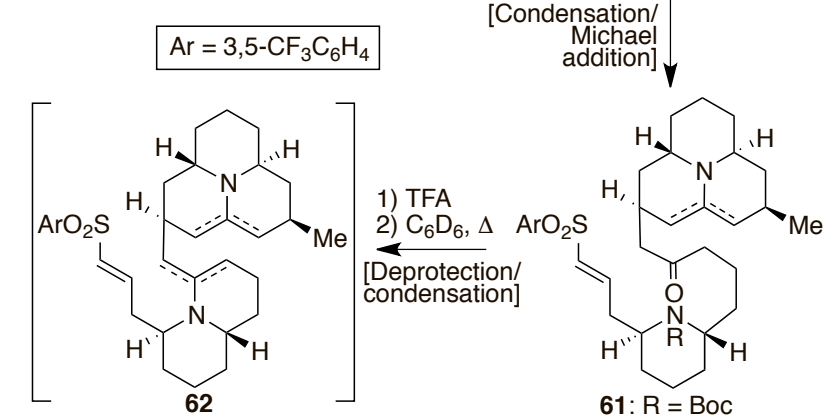

$$
\text { [Michael }
$$$$
\text { addition] }
$$
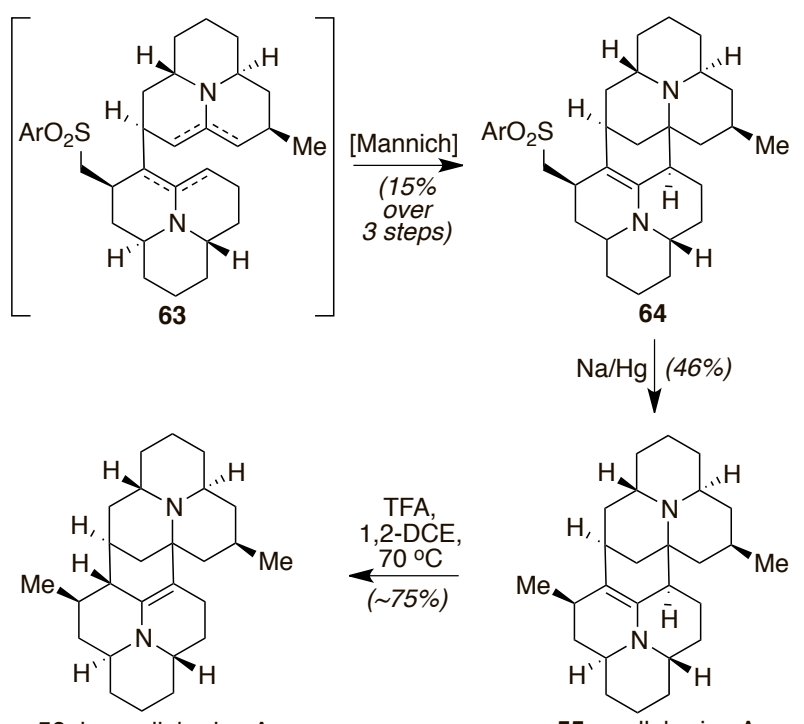

56: isopsylloborine A
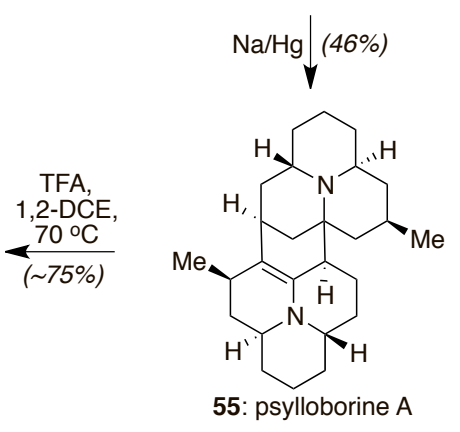

Scheme 6. Use of an 'intramolecular dimerization' strategy to access psylloborine A (55) and isopsylloborine $A$ (56) by initially linking at the key site where intermolecular bond formation did not occur and then folding each half of the molecule into the final material. unique radical reaction cascades to generate polycyclic and heterocyclic domains, distinct applications of pyrone Diels-Alder chemistry to generate diverse frameworks, complex cascades that can generate multiple bonds, rings, and stereocenters rapidly, and thoughts on how to achieve dimerizations when direct couplings fail. Current work is seeking to extend these findings, as well as uncover new opportunities for discovery as additional alkaloid classes are probed. If past history is any guide, many exciting findings await.

\section{Acknowledgments}

It is with deep thanks and appreciation that I recognize the efforts of all of my coworkers in the cited works as well as the current members of the group who are approaching new alkaloid targets in efforts seeking to make additional advances. Their collective energy, dedication, and creativity have made this research program a true pleasure to pursue. The efforts described in this submission have been generously supported by research funds from the National Institutes of Health (R01GM84994), Columbia University, The Scripps Research Institute, the University of Chicago, the Sloan Research Foundation, the Research Corporation for Science Advancement, BristolMyers Squibb, Eli Lilly, and Amgen. Coworker fellowship support from the National Science Foundation, the Swiss Benevolent Society of New York, Bristol-Myers Squibb, Daiichi-Sankyo, Kyoto University, and the Société de Chemie Industrielle is also gratefully acknowledged. I also thank again all those named in our original publications who facilitated our efforts, particularly structural elucidation through NMR, mass spectrometry, and X-ray crystallography. Charles Cole, Amanda Houser, Myles Smith, and Zhiyao Zhou are also acknowledged for helpful comments during the preparation of this manuscript.

Received: October 27, 2017 gram, particularly elements of the 'intramolecular dimerization' approach, to other alkaloid targets. For example, there are other cases where two monomers have been unable to be converted into a dimeric target with appropriate regiocontrol despite the existence of reasonable mechanistic proposals to do so. The myrmicarin family of defensive alkaloids ${ }^{[37]}$ is a salient example, where many efforts to convert myrmicarin 215A/B (65, Scheme 7) into myrmicarin 430A (66) have been met with failure, affording alternate stereoand regioisomers such as 67. ${ }^{[38]}$ We believe that an initial linking approach of acyclic precursors, followed by condensations to generate the respective polycyclic ring systems, could potentially succeed here as well. And, in a more recent synthesis of the heterodimeric Coccinellid alkaloid dimer exochomine (72), ${ }^{[39,40]}$ we found that it was essential in our efforts to merge two advanced fragments together through aldol chemistry that one of the pieces (68) have one of its final rings unforged. ${ }^{41]}$ This design was based on the idea of adding additional structural flexibility to its reactive domain, reflecting a tenet of an 'intramolecular dimerization' strategy in its broad terms. No other approach or intermediate probed was successful in enabling the two halves of this unique natural product to be brought together as effectively.

In conclusion, alkaloid natural products continue to afford immense opportunities for discovery, whether in the form of new reactions, distinct strategies, and/or novel tactics. From our perspective, the works recounted in this review were critical in inspiring several advances along these lines. These include an NHC-mediated cascade to forge bridging butenolides, several
[1] K. C. Nicolaou, T. Montagnon, 'Molecules that Changed the World', Wiley, 2008, pp. 366.

[2] a) K. C. Nicolaou, E. J. Sorensen, "Classics in Total Synthesis', Wiley-VCH, 1996, pp. 798; b) K. C. Nicolaou, S. A. Snyder, 'Classics in Total Synthesis II', Wiley-VCH, 2003, pp. 639; c) K. C. Nicolaou, J. S. Chen. 'Classics in Total Synthesis III', Wiley-VCH, 2011, pp. 746.

[3] M. Moudi, R. Go, C. Y. S. Yien, M. Nazre, Int J. Prev. Med. 2013, 4, 1231.

[4] For a summary of the early isolations of various Securinega alkaloids, see: V. Snieckus, 'The Securinega Alkaloids' in 'The Alkaloids', Ed. R. H. F. Manske, 1975, vol. 14, pp. 425-506.

[5] For syntheses up to the time of our work, see: a) S. Saito, H. Yoshikawa, Y. Sato, H. Nakai, N. Sugimoto, Z. Horii, M. Hanaoka, Y. Tamura, Chem. Pharm. Bull. 1966, 14, 313; b) C. H. Heathcock, T. W. von Geldern, Heterocycles $1987,25,75$; c) P. A. Jacobi, C. A. Blum, R. W. DeSimone, U. E. S. Udong, Tetrahedron Lett. 1989, 30, 7173; d) P. A. Jacobi, C. A. Blum, R. W. DeSimone, U. E. S. Dong, J. Org. Chem. 1991, 113, 5384; e) G. Han, M. G. LaPorte, J. J. Folmer, K. M. Werner, S. M. Weinreb, Angew. 
Scheme 7.

Application of 'intramolecular dimerization' concept elements to other alkaloid-based synthetic problems.
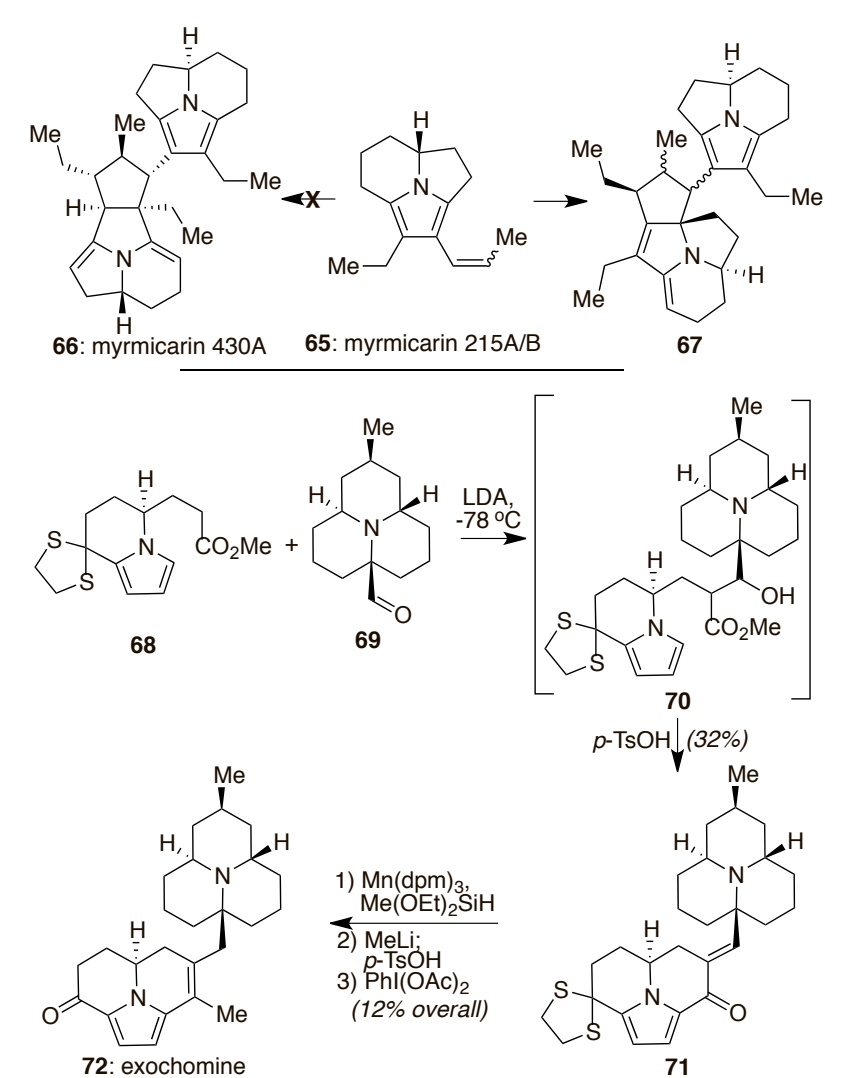

Kennett, S. Lightowler, D. N. Middlemiss, B. Trail, G. J. Riley, M. D. Wood, J. Med. Chem. 1998, 41, 1598; f) D. Liu, G. Zhao, L. Xiang, Eur. J. Org. Chem. 2010, 3975.

[18] For syntheses of mesembrine, see: a) M. Shamma, H. Rodriguez, Tetrahedron Lett. 1965, 6, 4847; b) S. Takano, Y. Imamura K. Ogasawara, Chem. Lett. 1981, 22, 1385; c) S. Takano, Y. Imamura, K. Ogasawara, Tetrahedron Lett. 1981, 22, 4479; d) A. I Meyers, R. Hanreich, K. T. Wanner, J. Am. Chem. Soc. 1985, 107, 7776; e) H. Nemoto, T. Tanabe, K. Fukumoto, J. Org. Chem. 1995, 60, 6785; f) S. E. Denmark, L. R. Marcin, J. Org. Chem. 1997, 62, 1675; g) J. H. Rigby, W. Dong, Org. Lett. 2000, 2, 1673; h) D. F Taber, Y. He, J. Org. Chem. 2005, 70, 7711; i) T. Paul, W. P. Malachowski, J. Lee, Org. Lett. 2006, 8, 4007; j) Y. Zhao, Y. Zhou, L. Liang, X. Yang, F. Du, L. Li, H. Zhang, Org. Lett. 2009, 11, 555

[19] For syntheses of gracilamine, see: a) S. Tian, W. Zi, D. Ma, Angew. Chem. Int. Ed. 2012 51, 10141; b) Y. Shi, B. Yang, S. Cai, S. Gao, Angew. Chem. Int. Ed. 2014, 53, 9539; c) S. Bose, J. Yang, Z. X. Yu, J. Org. Chem. 2016, 81,6757 ; d) N. Y. Gao, M. G. Banwell, A. C. Willis, Org. Lett. 2017, 19, 162; e) M. Odagi, Y. Yamamoto, K. Nagasawa, Angew. Chem. Int Ed. 2017, doi: 10.1002/anie.201708575; f) X. D. Zuo, S. M. Guo, R. Yang, J. H. Xie, Q. L. Zhou, Org. Lett. 2017, 19, 5240.

[20] P. Gei, M. W. Smith, N. R. Braffman, S. A. Snyder, Angew. Chem. Int. Ed. 2016, 55, 3625.

[21] K. Afarinkia, M. J. Bearpark, A. Ndibwami, J. Org. Chem. 2003, 68, 7158 .

[22] For example, see: a) D L Boger R. S. Coleman, J. Org. Chem. 1984, 49, 2240; b) K. C. Nicolaou, A. J. Roecker, J. A. Pfefferkorn, G. Q. Cao, J. Am. Chem. Soc. 2000, 122, 2966; c) A. Padwa, M. A. Brodney, M. Dimitroff, B. Liu, T. Wu, J. Org. Chem. 2001, 66, 3119; d) J. Li, T. Mei, J. Yu, Angew. Chem. Int. Ed. 2008, 47, 6452; e) T. Mei, X. Wang, J. Yu, J. Am. Chem. Soc. 2009, 131, 10806; f) T. S. Mei, D. Leow, H. Xiao, B. N. Laforteza, J. Q. Yu, Org. Lett. 2013 15,3058 .

Chem. Int. Ed. 2000, 39, 237; f) G. Han, M. G. LaPorte, J. J. Folmer, K. M. Werner, S. M. (inreb, J. Org. Chem. 2000, 65, 6293; g) G. , G. LaPorte, M. C. McIntosh, S. M. Honda, H. Namiki, M. Kudoh, N. Wantanabe, H. Nagase, H. Mizutani, Tetrahedron Lett 2000, 41, 5927; i) T. Honda, H. Namiki, M Kudoh, H. Nagase, H. Mizutani, Heterocycles 2003, 59, 169; j) S. Liras, J. E. Davoren, J. Bordner, Org. Lett. 2001, 3, 703; k) T. Honda, H. Namiki, K. Kaneda, H. Mizutani, Org Lett. 2004, 6, 87; 1) T. Honda, H. Namiki, N. Watanabe, H. Mizutani, Tetrahedron Lett. 2004, 45, 5211; m) R. Alibés, M. Ballbe, F. Busqué, P. De March, L. Elias, M. Figueredo, J. Font, Org. Lett. 2004, 6, 1813; n) R. Alibés, P. Bayon, P. De March, M. Figueredo, J. Font, E. GarciaGarcia, D. Gonzalez-Galvez, Org. Lett. 2005 , 7, 5107; o) C. A. Carson, M. A. Kerr, Angew. Chem. Int. Ed. 2006, 45, 6560; p) A. B. Leduc, M. A. Kerr, Angew. Chem. Int. Ed. 2008, 47, 7945; q) F. Busqué, M. Canto, P. De March, M Figueredo, J. Font, Tetrahedron: Asym. 2003 14, 2021; r) P. Liu, S. Hong, S. M. Weinreb, J. Am. Chem. Soc. 2008, 130, 7562; s) B. Dhudshia, B. F. T. Cooper, C. L. B. Macdonald, A. N. Thadani, Chem. Commun. 2009, 463; t) M. R. Medeiros, J. L. Wood, Tetrahedron 2010, 66, 4701; u) J.-H. Chen, S. R. Levine, J. F. Buergler, T. C. McMahon, M. R. Medeiros, J. L. Wood, Org. Lett. 2012, 14, 4531; v) A. S. Reddy, P. Srihari, Tetrahedron Lett. 2012, 53 , 5926; w) M. Sampath, P.-Y. B. Lee, T.-P. Loh, Chem. Sci. 2011, 2, 1988; x) H. Wei, C. Qiao, G. Liu, Z. Yang, C.-c. Li, Angew. Chem. Int. Ed. 2013, 52, 620 .

[6] For a recent review on the use of NHCs in total synthesis, see: J. Izquierdo, G. E. Hutson, D. T Cohen, K. A. Scheidt, Angew. Chem. Int. Ed. 2012, 51, 11686 .

[7] A. M. ElSohly, D. A. Wespe, T. J. Poore, S. A Snyder, Angew. Chem. Int. Ed. 2013, 52, 5789.
[8] M. S. Kerr, J. R. DeAlaniz, T. Rovis, J. Org. Chem. 2005, 70, 5725 A. Scheidt, Nat. Chem. 2010, 2, 766.

10] X.-H. Cai, Q.-G. Liu, Y.-P. Liu, T. Feng, Z.-Z. Du, W.-Q. Li, X.-D. Luo, Org. Lett. 2008, 10, 577.

[11] For a recent review, see: R. Eckermann, T. Gaich, Synthesis 2013, 45, 2813

[12] M. W. Smith, S. A. Snyder, J. Am. Chem. Soc. 2013, 135,12964

[13] P. A. Evans, T. Manangan, Tetrahedron Lett 1997, 38, 8165

[14] For radical-based approaches towards oxindoles, see: a) A. L. Beckwith, J. M. D. J. Storey, Chem. Soc., Chem. Commun. 1995, 977; b) A L. J. Beckwith, V. W. Bowry, W. R. Bowman, E. Mann, J. Parr, J.M. Storey, Angew. Chem. Int Ed. 2004, 43, 95.

[15] a) G. L. Adams, P. J. Carroll, A. B. Smith III, J. Am. Chem. Soc. 2012, 134, 4037; b) G. L. Adams, P. J. Carroll, A. B. Smith III, J. Am Chem. Soc. 2013, 135, 519.

[16] For a review, see: K. Afarinkia, V. Vinader, T. D. Nelson, G. H. Posner, Tetrahedron 1992, 48, 9111.

[17] For recent reviews and examples of these heterocycles, see: a) A. Rakhit, M. E. Hurley, V. Tipnis, J. Coleman, A. Rommel, H. R. Brunner, J. Clin. Pharmacol. 1986, 26, 156; b) $\mathrm{H}$ Matsuoka, N. Kato, K. Tsuji, N. Maruyama, H. Suzuki, M. Mihara, Y. Takeda, K. Yano, Chem. Pharm. Bull. 1997, 45, 1146; c) W. G. Kim, J. P. Kim, H. Koshino, K. Shin-Ya, H. Seto, I. D. Yoo, Tetrahedron 1997, 53, 4309; d) T. F Seeger, P. A. Seymour, A. W. Schmidt, S. H Zorn, D. W. Schulz, L. A. Lebel, S. McLean, V. Guanowsky, H. R. Howard, J. A. Lowe III, J. Heym, J. Pharmacol. Exp. Ther. 1995, 275, 101; e) S. M. Bromidge, S. Dabbs, D. T. Davies, D. M. Duckworth, I. T. Forbes, P. Ham, G. E. Jones, F. D. King, K. R. Mulholland, D. V. Saunders, P. A. Wyman, F. E. Blaney, S. E. Clarke, T. P. Blackburn, V. Holland, G. A.
[23] N. Ünver, G. I. Kaya, Turk. J. Chem. 2005, 29 547.

[24] H. K. Schnoes, K. Biemann, J. Mokry, I. Kompis, A. Chatterjee, G. Ganguli, J. Org. Chem. 1966, 31, 1641.

[25] a) J. Moreno, E. Picazo, L. A. Morrill, J. M. Smith, N. K. Garg, J. Am. Chem. Soc. 2016, 138, 1162; b) W. Ren, Q. Wang, J. Zhu, Angew. Chem. Int. Ed. 2016, 55, 3500; c) D. Nishiyama, A. Ohara, H. Chiba, H. Kumagai, S. Oishi, N. Fujii, H. Ohno, Org. Lett. 2016, 18, 1670; d) R. Eckermann, M. Breunig, T. Gaich, Chem. Commun. 2016, 52, 11363; e) R. Eckermann, M. Breunig, T. Gaich, Chem. Eur. J. 2017, 23 , 3938; f) X. Xie, B. Wei, G. Li, L. Zu, Org. Lett. 2017, 19, 5430; g) T. Xiao, Z.-T. Chen, L.-F. Deng, D. Zhang, X.-Y. Liu, H. Song, Y. Qin, Chem. Commun. 2017, doi:10.1039/ C7CC08153G

[26] M. W. Smith, Z.Zhou, A. X. Gao. T. Shimayashi, S. A. Snyder, Org. Lett. 2017, 19, 1004.

[27] For Cu-based precedent, see: a) D. R. Fandrick, K. R. Fandrick, J. T. Reeves, Z. Tan, W. Tang, A. G. Capacci, S. Rodriguez, J. J. Song, H. Lee, N. K. Yee, C. H. Senanayake, J. Am. Chem. Soc. 2010, 132, 7600; b) E. M. Vieira, F. Haeffner, M L. Snapper, A. H. Hoveyda, Angew. Chem. Int. Ed. 2012, 51, 6618; c) X.-F. Wei, Y. Shimizu, M. Kanai, ACS Cent. Sci. 2016, 2, 21.

[28] For some related cyclizations, see: a) W. Xu, W Wang, X. Wang, Angew. Chem. Int. Ed. 2015, 54, 9546; b) Y. Liu, W. Xu, X. Wang, Org. Lett. 2010, 12, 1448; c) L. Zhang, Y. Wang, Z. J. Yao, S. Wang, X. Z. J. Yu, J. Am. Chem. Soc. 2015 137, 13290. 
[29] N. Peube-Locou, M. Plat, M. Koch, Phytochemistry 1973, 12, 199.

[30] For a review, see: A. G. King, J. Meinwald, Chem. Rev. 1996, 96, 1105.

[31] For selected isolation references, see: a) K. D. McCormick, A. B. Attgalle, S.-C. Xu, A. Svatoš, J. Meinwald, Tetrahedron 1994, 50, 2365; b) X Shi, A. B. Attygalle, J. Meinwald, Tetrahedron 1995, 51, 8711; c) Q. Huang, A. B. Attygalle, J. Meinwald, M. A. Houck, T. Eisner, J. Nat. Prod. 1998, 61, 508; d) F. C. Schröder, T. Tolasch, Tetrahedron 1998, 54, 12243; e) B. Lebrun, J.C. Braekman, D. Daloze, P. Kalushkov, J. M. Pasteels, Tetrahedron Lett. 1999, 40, 8115.

[32] For representative syntheses of the monomeric coccinellid alkaloids, see: a) W. A. Ayer, K. Furuichi, Can. J. Chem. 1976, 54, 1494; b) R. V. Stevens, A. W. M. Lee, J. Am. Chem. Soc. 1979, 101, 7032; c) R. H. Mueller, M. E. Thompson, R. M. DiPardo, J. Org. Chem. 1984, 49, 2217 d) A. I. Gerasyuto, R. P. Hsung, J. Org. Chem. 2007, 72, 2476; e) S. Fujita, T. Sakaguchi, T. Kobayashi, H. Tsuchikawa, S. Katsumura, Org. Lett. 2013, 15, 2758.

[33] For reviews, see: a) K. W. Quasdorf, L. E. Overman, Nature 2014, 516, 181; b) A. Hager,
N. Vrielink, D. Hager, J. Lefranc, D. Trauner, Nat. Prod. Rep. 2016, 33, 491

[34] T. C. Sherwood, A. H. Trotta, S. A. Snyder, J. Am. Chem. Soc. 2014, 136, 9743.

[35] Y. Yamada, D. Miljkovic, P. Wehrli, B. Golding, P. Loliger, R. Keese, K. Muller, A. Eschenmoser, Angew. Chem. Int. Ed. Engl. 1969, 8, 343.

[36] Our work towards the resveratrol class of oligomers is one example: a) S. A. Snyder, A. L. Zografos, Y. Lin, Angew. Chem. Int. Ed. 2007, 46, 8186; b) S. A. Snyder, S. P. Breazzano, A. G. Ross, Y. Lin, A. L. Zografos, J. Am. Chem. Soc. 2009, 131, 1753; c) S. A. Snyder, A. Gollner, M. I. Chiriac, Nature, 2011, 474, 461; d) S. A. Snyder, N. E. Wright, J. J. Pflueger, S. P. Breazzano, Angew. Chem. Int. Ed. 2011, 50, 8629; e) S. A. Snyder, Z. G. Brill, Org. Lett. 2011, 13, 5524; f) S. A. Snyder, S. B. Thomas, A. C. Mayer, S. P. Breazzano, Angew. Chem. Int. Ed. 2012, 51, 4080; g) N. E. Wright, S. A. Snyder, Angew. Chem. Int. Ed. 2014, 53, 3409; h) T. H. Jepsen, S. B. Thomas, Y. Lin, C. I. Stathakis, I. de Miguel, S. A. Snyder, Angew. Chem. Int. Ed. 2014, 53, 6747.

[37] a) W. Francke, F. Schröder, F. Walter, V. Sinnwell, H. Baumann, M. Kaib, Liebigs
Ann. 1995, 965; b) F. Schröder, S. Franke, W. Francke, H. Baumann, M. Kaib, J. M. Pasteels, D. Daloze. Tetrahedron 1996, 52, 13539; c) F. Schröder, V. Sinnwell, H. Baumann, M. Kaib, Chem. Commun. 1996, 2139; d) F. Schröder, V. Sinnwell, H. Baumann, M. Kaib, W. Francke, Angew. Chem. Int. Ed. Engl. 1997, 36, 77.

[38] For representative examples, see: a) A. E. Ondrus, M. Movassaghi, Tetrahedron 2006, 62, 5287; b) M. Movassaghi, A. E. Ondrus, B. Chen, J. Org. Chem. 2007, 72, 10065; c) S A Snyder, A. M. ElSohly, F. Kontes, Angew. Chem. Int. Ed. 2010, 49, 9693.

[39] M. Timmermans, J.-C. Braekman, D. Daloze, J. M. Pasteels, J. Merline, J.-P. Declerq, Tetrahedron Lett. 1992, 33, 1281.

[40] For the only synthetic study towards this target to date, see: J. C. Shattuck, J. Meinwald, Tetrahedron Lett. 1997, 38, 347.

[41] A. X. Gao, T. Hamada, S. A. Snyder, Angew. Chem. Int. Ed. 2016, 55, 10301. 